\title{
Tangled Up in Blue sysobriale
}

Climate change is forcing critically endangered North Atlantic right whales into conflict with commercial fishing gear-and the whales are suffering devastating losses. Entanglement response teams take great risks to rescue individual animals, but they cannot save the species.

"One step and you're bait" is a cautionary maxim used by the Campobello Whale Rescue Team. It's a fisherman's saying, which makes sense because commercial fishermen have always been part of the team, including Mackie Greene and Joe Howlett, who formed it in 2002 with the support of the late Jerry Conway, a Fisheries and Oceans Canada (DFO) marine mammal advisor.

Lessons learned dropping trawls of heavy traps translate directly to handling lines attached to struggling 50-ton whales. In either situation, one step into a coil of running line offers an excellent chance to experience what Herman Melville noted in Moby-Dick as the fate of many an old-time whaler: "a speechlessly quick chaotic bundling of a man into eternity."

New entanglement responders quickly develop catchpoint paranoia. "Always be checking your PFD," says Greene. "No strings or buckles hanging, no rings on your fingers. Make sure you and everybody else is clear of the line. And make sure it's not caught on the boat."

The Campobello team's old boat was missing the safety line that is standard on Zodiacs. "We had a carabiner get caught in the lifeline when the other end was attached to a big right whale," says Greene. "Pop, pop, pop, just tore the lifeline right off."

Working from small boats down at blowhole level, entanglement responders typically first grapple onto whatever is wrapped around a whale. They then use the ancient whaling technique of adding drag to attempt to slow the whale-a method modernized in 1984 by Charles "Stormy" Mayo and Dave Matilla at Provincetown's Center for Coastal Studies.
Over the years, responders have also designed custom cutting grapples as well as fixed and flying (detachable) knives that are wielded on long rescue poles. They've even repurposed and modified weapons like broadhead crossbow bolts into lifesaving tools. Once a team readies to cut a whale free, though, it still almost always means entering what they call the danger zone.

BELOW. Entanglement Responders from the Florida Fish and Wildlife Conservation Commission and the Georgia Department of Natural Resources use a cutting grapple to remove $300 \mathrm{~m}$ of rope from a North Atlantic right whale named FDR, catalog \#4057. The entanglement caused severe wounds, including to the whale's blowhole. FDR was last seen in 2016 after being entangled again and partially cut free. Photo credit: Florida Fish and Wildlife Conservation Commission, NOAA research permit \#15488. 
TOP. Entanglement responders cut line from Ruffian (NARW \#3530) using a flying knife. The whale dragged line and a $61 \mathrm{~kg}$ crab trap from the Gulf of St. Lawrence to Florida, causing extensive injuries. Ruffian has survived at least two entanglements and was last seen in 2020 in Cape Cod Bay. Photo credit: Georgia Department of Natural Resources and Florida Fish and Wildlife Conservation Commission, taken under NMFS permit \#18786 BOTTOM. The Campobello Whale Rescue Team, including Jerry Conway, Moira Brown, and Mackie Greene, with Joe Howlett at the bow, works to free FDR from his second entanglement in August 2016 in the Bay of Fundy. Photo credit: Philip Hamilton, Anderson Cabot Center at the New England Aquarium under DFO SARA permit

In the Western North Atlantic, the two large whales that responders most frequently work on are humpbacks and North Atlantic right whales (NARW). Both are "fight" species willing to confront perceived dangers as opposed to "flight" species like blue whales, finbacks, and minkes that try to outrun threats. Humpbacks are armed with the world's longest pectoral fins, and NARW with intimidating skulls, but for both species their main weapon is the tail. The flukes may appear floppy from a distance, but Stormy Mayo-who's found them in his lap during disentanglementsdescribes them as feeling like "an innertube filled with lead."

Of the two species, NARW, Eubalaena glacialis, are considered much more dangerous to approach. "A humpback will easily kill you," says Mayo, who's worked on dozens of both species. "But a right whale will absolutely squash you."

As stout as they appear, NARW are remarkably flexible. "A right whale can take its fluke and touch it to its nose," says Scott Landry, Director of the of the Center for Coastal Studies' Marine Animal Entanglement Response Program. "So, any threat that approaches its head is going to be crushed."

Unfortunately for responders, NARW often encounter fishing gear while feeding, and ropes typically get caught in their mouths. This usually requires maneuvering into the whale's kill zone to cut them free.

"And if that whale wants to take a swipe at you," says Mackie Green, "there's not much you can do except try and get the hell out of there as quick as you can." Mackie pauses for a tough moment after saying this, and then adds: "Something else that's now in the book is that when things go bad, the whale's close, and things start slapping, everybody should try and lay down and get some protection from the sides of the boat."

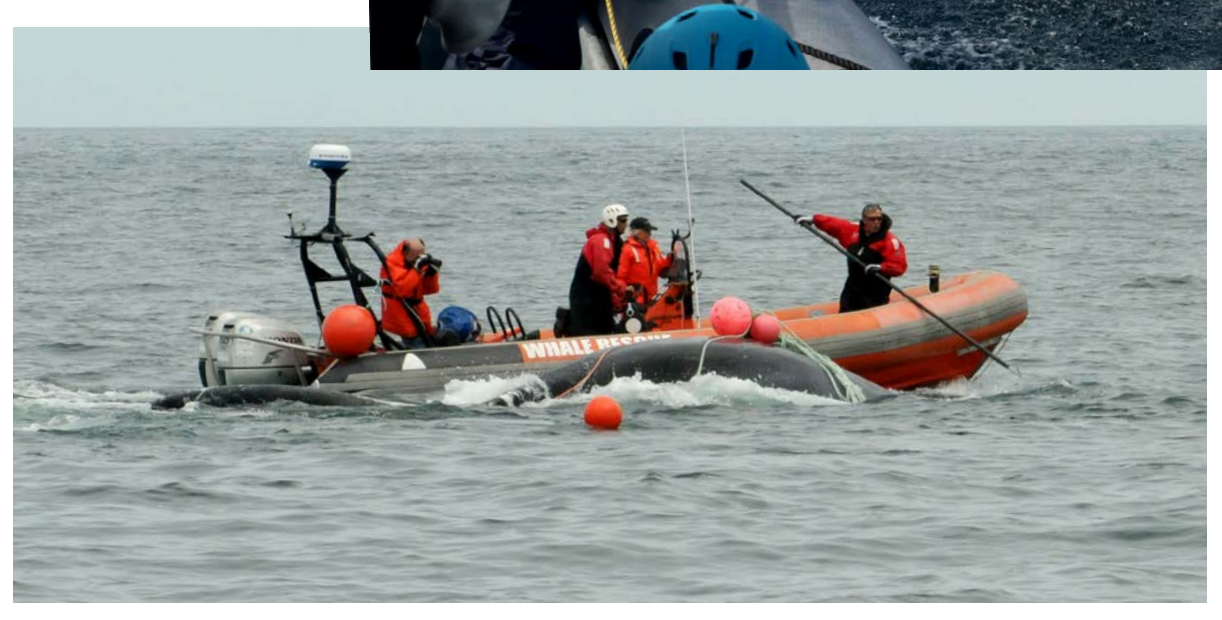

That new protocol is in there because of what happened to his friend and teammate, Joe Howlett.

Tales of the strength and stubbornness of NARW seemed apocryphal until a whale named Ruffian proved all the legends true. With estimates of fewer than 360 NARW remaining (NARWC, 2021a), researchers know practically every individual in the critically endangered population and have given many of them mnemonic nicknames so they can be recognized on sight. Ruffian is a big male born in 2004 and badly wounded at age five by an entanglement, leaving him with tough guy scars. In January 2017, a survey plane spotted Ruffian off the southeast US coast with a thick line running through his mouth and taut across his back where it chewed at a raw, gaping wound. In disentanglement triage, a line through the mouth or a constricting wrap around any body part is considered life-threatening. A line around the head can prevent the animal from feeding, and it will slowly starve. A wrap around flippers or tail will gradually, excruciatingly saw through flesh and bone until it amputates the limb. Body wraps can flense skin and blubber, leaving the whale to bleed out or die from infection unless the drag from the gear drowns or starves them to death first.
"Of all the ways we kill wild animals, this has got to be the worst-slow and gruesome," says Michael Moore, a veterinarian and director of Woods Hole Oceanographic Institution's Marine Mammal Center. Moore has performed necropsies on 43 right whales, literally wading into the damage we've done to look for solutions. "It's torture."

From studying scars, researchers have determined that nearly all NARW have experienced this torture. At last count, $87 \%$ of them have been entangled at least once, $59 \%$ more than once, and some individuals have been caught in fishing gear more than six times (Hamilton et al., 2019).

Ruffian was one of the lucky ones. In a two-day operation, disentanglement crews from Georgia and Florida successfully cut him free. The tackle they collected was snow crab gear from the Gulf of St. Lawrence. That means Ruffian swam at least $2,575 \mathrm{~km}$ while hauling $137 \mathrm{~m}$ of thick line that bit into him every time he beat his tail. Even more amazing, the $61 \mathrm{~kg}$ metal crab trap was still attached and likely dragging along the bottom whenever he swam into shallow water during the months-long ordeal. That incredible feat of strength, stamina, and pain tolerance is testament to the right whale's will to survive.

Left alone, a NARW might live 80 or more years like their southern right whale 
had become a billion-dollar fishery. As hungry right whales rounded Nova Scotia and entered the Gulf of St. Lawrence in search of food, they swam headlong into a big-ship speedway and a deadly maze of high-tensile plastic rope.

"It was like a war zone," says Scott Kraus of the New England Aquarium. The casualties began on June 6 with the body of a 10-year-old male floating north of Prince Edward Isle. On the $18^{\text {th }}$ it was Panama, a 17-year-old, then Glacier, 33, who died of internal hemorrhage on the 19th. "These were ship strikes," says Moe Brown. "There's nothing in nature that can cause that kind of damage to a right whale."

Starboard was an 11-year-old female at the beginning of her reproductive life. She was found dead, entangled in snow crab gear on the $21^{\text {st }}$. Next it was Contrail, another precious young female. It is impossible to overstate the value of each female NARW to the species. Just two of them, Kleenex-now presumed dead from a long-term entanglement-and another prodigious breeder named Baldy, have generated $10 \%$ of the entire population.

To Joe Howlett, 59 and father of two, seeing these animals he loved getting knocked off one after the other was intolerable. Howlett had already saved one whale that season, an entangled female NARW he cut free from Shelagh on July 7.

"That was great," says Hamilton, who was aboard the cruise. "Joe and I gave each other a big hug, 'Yeah, we did it!' But the good feeling was short-lived."

On the $10^{\text {th }}$, a DFO Fast Response Craft (FRC) picked up Howlett and Hamilton and rushed them out to another whale. This one, says Hamilton, had snow crab line wrapped at least 10 times around his body.

Alone at the bow, like Queequeg in wraparound shades and hefting a rescue pole instead of a harpoon, Joe signaled the FRC driver to edge in close. Eyeing the rope strung through the whale's baleenfilled mouth and wrapped around and around his bulky black frame, Joe looked for the key to undoing this gargantuan Gordian knot.

"Rope from the Gulf, crab fishery ropes, are thick and hard to cut," says Mackie Greene. Catching more than one piece of this line could be too much for a knife to slice through, risking the blade getting stuck and the pole getting ripped out of a responder's hands. But Joe was a strong guy, his arms muscled from fishing and playing ice hockey. He reached out, hooked a V-shaped fixed knife onto a line at the whale's mouth, yanked, and it parted.

"Joe turned, gave us a thumbs up and yelled 'We're doing it!" remembers Hamilton. The whale reacted and slashed its tail at the FRC. "It soaked the boat," says Hamilton, "but then it just kept swimming."

Howlett waved the boat back in toward Ruffian. He reached far out and slid his knife under another wrap. Just as he tugged, though, the whale turned toward the boat and dived. "Joe was leaning out over the edge of the boat," says Hamilton, "with the pole straight up and down."

If the whale managed to pull the pole out of Joe's hands it would lose its one chance to survive. Howlett wasn't going to let that happen. He heaved and finally the knife sliced through the line.

Howlett flashed the crew another grinning thumbs up as he yelled, "I got it! I got it!" He turned back toward the bow just in time to see the massive tail rising out of the water.

The dorsal side of the whale's flukes whipped the FRC with a backhand slap. Hamilton looked up to see half of the 4.5-meter-wide tail filling the entire bow of the boat, and his friend collapsed on the deck.

Hamilton performed CPR on Howlett for more than an hour and a half as the FRC raced back to Shelagh and then to a Canadian Coast Guard cutter. But Howlett never regained consciousness and was pronounced dead when they reached the dock at Shippagan, New Brunswick.

Later that day, the whale was spotted by an aerial survey team. It was identified as \#4123, one of Kleenex's grandsons. He was free of the entangling gear. Joe's final cut was a success.

Since Howlett's death, the Canadian and US entanglement networks have adjusted safety protocols, particularly when it comes to NARW. DFO has invested in the Campobello Whale Rescue Team, finally providing new boats and more operational funding. The tragedy raised the profile of disentanglement work and increased support, but the fact remains that courageous folks with sharp knives on small boats is not the solution to saving NARW. Entanglement responders continue to fight a desperate and dangerous rearguard action, battling to rescue individual whales and delay population decline until changes in fishing practices can greatly reduce entanglement rates.

The Holy Grail-and perhaps the only hope to prevent North Atlantic right whales from going extinct-is "ropeless" fishing gear, where traps are dropped with no buoy lines to the surface. When fishers want to retrieve their catch, they ping a receiver that releases a float and line or activates a pump to make the pot itself positively buoyant. There's pushback from the fishing industry over cost and reliability issues. NOAA and DFO are countering that with research grants along with the stick of more fishing closures and the associated carrot of potentially allowing ropeless gear in closed areas.

Until then, entanglement responderswho see reasonable commercial fishers as allies in their efforts-will continue to launch and save whales. However, as the Center for Coastal Studies' Scott Landry says, he wishes that a real solution to the problem would put all response teams out of work tomorrow. 饮

\section{REFERENCES}

Hamilton, P.K., A.R. Knowlton, M.N. Hagbloom, K.R. How, M.K. Marx, H.M. Pettis, A.M. Warren, and M.A. Zani. 2019. Maintenance of the North Atlantic Right Whale Catalog, Whale Scarring and Visual Health Databases, Anthropogenic Injury Case Studies, and Near Real-Time Matching for Biopsy Efforts, Entangled, Injured, Sick, or Dead Right Whales, https://www.narwc.org/ uploads/1/1/6/6/116623219/catalog_report-2020 _-_final.pdf

Meyer-Gutbrod, E.L., C.H. Greene, K.T.A. Davies, and D.G. Johns. 2021. Ocean regime shift is driving collapse of the North Atlantic right whale population. Oceanography 34(3):22-31, https://doi.org/ 10.5670/oceanog.2021.308.

NARWC (North Atlantic Right Whale Consortium). 2021a. North Atlantic Right Whale Consortium Databases. New England Aquarium, Boston, MA, https://www.narwc.org/narwc-databases.html.

NARWC. 2021b. Right Whale News 29(2),

https://www.narwc.org/uploads/1/1/6/6/116623219/ rwn_may21.pdf.

Pace, R.M. III, R. Williams, S.D. Kraus, A.R. Knowlton, and H.M. Pettis. 2021. Cryptic mortality of North Atlantic right whales. Conservation Science and Practice 3(2):e346, https://doi.org/10.1111/csp2.346.

Pettis, H.M., R.M. Pace III, and P.K. Hamilton. 2018. North Atlantic Right Whale Consortium 2018 Annual Report Card. Report to the North Atlantic Right Whale Consortium, https://www.narwc. org/uploads/1/1/6/6/116623219/2018report_ cardfinal.pdf.

\section{AUTHOR}

Bob Friel (bob@seadocsociety.org) is a writer and the producer of the science/adventure series Salish Sea Wild and has been a member of the Large Whale Entanglement Response Network since 2015. $\mathrm{He}$ is affiliated with the SeaDoc Society, University of California Davis Karen C. Drayer Wildlife Health Center, Orcas Island Office, Eastsound, WA, USA.

\section{ARTICLE DOI}

https://doi.org/10.5670/oceanog.2021.313 